\title{
Ideologia em estado puro: Juros e inflação para além da aparência neoclássica
}

\author{
Ideology on pure state: Interest and inflation \\ beyond the neoclassical appearance
}

JORGE ARMINDO AGUIAR VARASCHIN*

RESUMO: Há uma crença em parcela dos/as economistas brasileiros/as alusiva à possibilidade de análises econômicas que excluam influências ideológicas. A ortodoxia neoclássica funda sua pretensão científica apoiada na premissa de sua própria neutralidade, influindo no debate econômico nacional: o não reconhecimento de seu caráter ideológico, conforme esvazia de significação conceitos centrais como a inflação, interdita a discussão da qual faz parte. Este trabalho investiga esse deslocamento de conteúdo, cuja síntese manifesta-se através da temática inflacionária, apresentando esse "vazio" conceitual como momento de perda de sua eficácia analítica, mas que, justamente por isso, redimensiona seu papel como veículo ideológico.

PALAVRAS-CHAVE: Economia Brasileira; Ideologia; Inflação; Significante.

ABSTRACT: There is a belief amongst part of Brazilian economists alluding to the possibilities of economic analysis which excludes ideological influences. The neoclassical orthodoxy establishes its scientific pretentions based on the premise of its own neutrality, influencing the national economic debate: the not recognizing of its ideological character, as it drains significant focal concepts such as inflation, inhibits the discussion from which it belongs. This essay queries such content shift, which synthesis prompts through the inflationary thematic. Featuring this conceptual "void" as moment of loss from its analytical efficacy, though, because of it, resizes its part as ideological mean.

KEYWORDS: Brazilian Economy; Ideology; Inflation; Significant.

JEL Classification: B410; B590; Z00.

\footnotetext{
* Doutorando em Economia do Desenvolvimento pelo Programa de Pós-Graduação em Economia da Universidade Federal do Rio Grande do Sul (UFRGS). E-mail: j_varaschin@yahoo.com.br. Submetido: 20/Julho/2016; Aprovado: 21/Fevereiro/2017.
} 


\section{INTRODUÇÃO}

Há um chiste freudiano bastante conhecido no qual dois judeus discutem da seguinte maneira: “'Aonde vai?’, perguntou um. ‘À Cracóvia', foi a resposta. 'Como você é mentiroso!', não se conteve o outro. 'Se você dissesse que ia à Cracóvia, você estaria querendo fazer-me acreditar que estava indo a Lemberg. Mas sei que, de fato, você vai à Cracóvia. Portanto, por que você está mentindo para mim?'”(FREUD, 1905 [1996]), p. 77). A pergunta sugere a existência anterior de um código implícito de engano, quebrado por um dos personagens, quando, indo para Cracóvia, relata seu destino de fato. Código semelhante parece haver no debate econômico brasileiro: há algo de engano, fora de lugar, do modo que a discussão parece esconder alguma coisa para além das variáveis em estudo, algo que não é dito e que deve continuar não sendo. Nesse artigo, considera-se que esse é o drama criado pelas análises supostamente não ideológicas que inundam a ortodoxia econômica: o aparente paradoxo de não dizer o que efetivamente está sendo enunciado. O neoclassicismo ergue-se a partir da fé em investigações desnudas de ideologia ou, em outras palavras, neutras em relação à própria verdade virtual que constrói ${ }^{1}$. Apesar disso e das variadas tentativas de mascarar a ideologia (e, principalmente, de se mascarar perante a ideologia), considera-se, neste trabalho, que essa pretensa neutralidade não encontra espaço no mundo real, tornando necessário uma nova problematização da atual conjuntura do debate econômico nacional.

Contrariamente à premissa ortodoxa, a investigação do discurso que permeia as correntes neoclássicas demonstra que, justamente quando se supõe que a ideologia apareça fora do quadro de análise, encontra-se, pelo contrário, de maneira pura no próprio relato que engendra sua negação. Tem-se, portanto, que o momento onde se estabelece a crença de que há a possibilidade de uma análise absoluta das variáveis é o momento onde se encontra a ideologia em estado puro, onde esta se depara com seu próprio excesso. Nesse estudo, considera-se que o debate econômico atual faz precisamente isso: ao contrário de, como pretende, analisar o recente contexto econômico de maneira isolada, confinando dados no exterior do arcabouço ideológico, a própria análise, à medida que exterioriza a ideologia, reafirma inversamente sua consistência. Assim, a ideologia não se cristaliza quando "distorce" ou "esconde" certo aspecto do real, mas quando distorce e nega a si mesma.

Dessa forma, este artigo se propõe a construir algumas considerações quanto ao aspecto ideológico que cerca as atuais interpretações e análises da economia brasileira, a partir da economia política marxiana e da psicanálise de Jacques Lacan. O objetivo principal é desmistificar a fé ortodoxa em estudos ideologicamente neutros, considerando de maneira pormenorizada o papel da temática inflacionária no interior da narrativa neoclássica, já que, da maneira como é expos-

\footnotetext{
${ }^{1}$ Ver, por exemplo, a separação entre economia positiva e normativa em KEYNES (1890 [1955]), e FRIEDMAN (1953 [1966])
} 
ta, como relação exclusiva com certo ponto ou objeto da realidade em detrimento da própria realidade, esta crença mais se parece com um fetiche (FREUD, 1905 [1996]). A partir daí, pergunta-se: o que, de fato, está sendo discutido entre os/as economistas? Desse ponto, elaboram-se quatro hipóteses norteadoras: a ortodoxia, na medida em que supostamente retira a ideologia como pressuposto básico de seus conceitos, torna-os deslocados de seu próprio sentido, esvaziando sua eficácia analítica e redimensionando seu papel como significante (LACAN, 1966 [1998]), ou seja, como composição referencial de determinado discurso ideológico. O resultado é um discurso que interdita o próprio debate, não pela aparência, pelo silêncio de uma das partes, mas por aparentemente não "saber do que fala". Dessa forma, elabora, através da aparência de diálogo, sua efetiva não ocorrência; a segunda hipótese afirma que a discussão em si também faz parte do cenário econômico e, por isso, deve ser analisado conjuntamente como momento de sua reflexão. Em síntese, o imaginário acerca dos problemas econômicos atuais são os problemas econômicos atuais, não propriamente os fatos que os corroboram, mas justamente a consciência de que há algo errado, o que define a análise ideológica como central no estudo dos cenários econômicos; já a terceira hipótese redimensiona o papel dos juros no debate econômico nacional, apresentando-se como o assunto a ser deslocado, encoberto em certa medida pela temática inflacionária. Por isso, a inflação no Brasil traz intrinsecamente o que se chamou neste trabalho de semblante dos juros, ou seja, os traços indeléveis do que se esconde; por fim, considera-se que a condição de possibilidade para um debate genuíno surge a partir do reconhecimento do aspecto ideológico do espaço identificatório daquele que fala. Não há uma disputa entre "ideológicos" e "não ideológicos". O que ocorre são campos discursivos que se constroem no próprio reconhecimento de sua verdade virtual, isto é, de sua ideologia.

\section{O DEBATE DESLOCADO: A LÓGICA DO "SOCO NA MESA"}

Há um interessante relato de um debate sobre sistemas de taxas de câmbio², cujo mediador, ao ser questionado sobre a consistência de uma de suas afirmações (defesa de taxa de câmbio flutuante), responde de maneira pouco usual: "O que você sugere? Que voltemos aos tempos da inflação anterior ao Real?”. Essa discussão demonstra de maneira bastante satisfatória a atual dinâmica do debate econômico no país: conceitos básicos esvaziados de significação praticamente impossibilitam um diálogo genuíno. No exemplo, manifesta-se o papel proibidor que a temática inflacionária impele, ou seja, na medida em que se apresenta, surge como elemento que esvazia a possibilidade do contraponto. Nesse caso, a chama-

\footnotetext{
${ }^{2}$ Ver NASSIF (2016). Disponível em: http://jornalggn.com.br/noticia/as-marolas-pre-reuniao-do-copom. Acessado em: jan. 20 de 2016.
} 
da "memória inflacionária" ${ }^{3}$ amplia seu sentido tradicional. Não se apresenta apenas como um elemento que se propõe a explicar determinado tipo de ação social, específico para cenários de conflito distributivo ${ }^{4}$; pelo contrário: surge trazendo consigo uma série de medos e ansiedades. Na citação, essa "memória" foi utilizada não por necessidade lógica, na defesa de determinada proposição econômica, mas como um "pavor inflacionário", uma espécie de terror cuja finalidade é silenciar e deslegitimar o argumento que diverge. Como revelado anteriormente, o que se mostra é um esvaziamento do conceito, ou melhor, um deslocamento de sua função, surgindo uma paisagem bastante curiosa: a inflação que aparece na teoria econômica não é a mesma proferida no debate que esta fomenta. No primeiro caso, aparece seu uso lógico em perspectiva, referente à teoria elaborada; no segundo, a construção de um imaginário coletivo, disputado cotidianamente, mas cuja hegemonia pertence a um discurso específico. Esse deslocamento é típico da formação ideológica e exterioriza o conceito que a encarna. Assim, como já referido, nos dois momentos não se discorre sobre a mesma inflação, já que a palavra compõe duas funções: de conceito teórico e de veículo ideológico, o que a transforma, como elemento de uma rede, passível de se apresentar como o que Lacan chamou de significante (LACAN, 1966 [1998]). Na exposição, o efeito dessa dupla finalidade revela-se no mecanismo da aparência: o debate continua na forma, mas se esvai no conteúdo, na proibição gerada. Pensemos no tipo de resposta que a pergunta impõe. Quem, afinal, gostaria de taxas de inflação tão elevadas quanto às existentes no período anterior ao Real? Evidentemente, o questionamento não servia à função estrita de ouvir o outro, sua posição e argumento. Pelo contrário, por trás da aparente solicitação de uma resposta, há uma ordem implícita, não falada, mas imposta: "Não duvide!".

\section{OS SIGNIFICANTES E A IDEOLOGIA: A “EX-SISTÊNCIA” LACANIANA}

A lógica do significante expõe o aspecto primordial para a formação de determinado discurso. O significante fundamenta, como conceito básico, a tríade lacaniana, formada pelos campos do Simbólico, do Real e do Imaginário: o primeiro relacionado à diversidade de regras e pressupostos elementares de reconhecimento e socialização que nos insere no que se poderia chamar de ordem simbólica; o segundo campo, o Real, aparece como aquilo que escapa à simbolização ou, como exposto por Zizek, “[...] o real, em sua forma mais radical, tem de ser totalmente dessubstancializado. Ele não é uma coisa externa que resista a se deixar apanhar

\footnotetext{
${ }^{3}$ Para uma apresentação mais pormenorizada sobre o papel da memória inflacionária no interior da teoria inercialista, ver, por exemplo, BRESSER-PEREIRA e NAKANO, 1984.

${ }^{4}$ Ver, por exemplo, descrição de BRESSER-PEREIRA (2010) sobre o debate, no decorrer da formação da teoria da inflação inercial, entre os defensores das expectativas racionais e o que chamou de expectativas reais.
} 
na rede simbólica, mas as fissuras dentro dessa própria rede simbólica" (ZIZEK, 2006 [2010], p. 91); por fim, o Imaginário, apresentado como operativo do deslocamento ou nossa maneira de operar junto ao chamado grande Outro, isto é, à ordem simbólica.

O significante é uma categoria formal, e não descritiva. Pouco importa o que ele designa; por exemplo, tomamos aqui a figura do sintoma, mas o significante pode, da mesma forma, ser um lapso, um sonho, o relato do sonho, um detalhe desse relato, ou mesmo um gesto, um som, ou até um silêncio ou uma interpretação do psicanalista. [...] O significante é desprovido de sentido, não significa nada e, portanto, não entra na alternativa de ser explicável ou inexplicável. [...] Numa palavra, o significante é, e nada mais. O significante é, sim, desde que permaneça ligado a um conjunto de outros significantes: é Um entre outros com os quais se articula. Embora o significante Um seja perceptível para o analisando ou o analista, os outros com que se encadeia não o são. Estes são significantes virtuais, atualizados no passado ou ainda não atualizados. A articulação entre Um e os outros é tão estreita que, ao se pensar no significante, nunca se deve imaginá-lo sozinho. Um aforismo lacaniano resume bem essa relação: um significante só é significante para outros significantes. (NASIO, 1992 [1993], p. 17)

Nesse contexto, conforme a citação de NASIO (1992 [1993], p. 17), o significante opera justamente nas brechas do verbo. Lembremos da afirmação anterior de que a inflação, como veículo ideológico, nega sua face teórica, de ferramenta eficaz de estudo: como significante, a temática inflacionária é, não possuindo importância analítica. Não é por acaso a existência de inúmeras teorias sob a dinâmica do processo inflacionário. Não apenas as determinações e causas do fenômeno aparecem de maneira obscura, mas esse é o próprio jogo do significante: no interior do discurso ideológico neoclássico a inflação é, independente de qualquer relação causal. Não serve para explicar algum fenômeno específico, mas para constituir, justificar e legitimar ideologicamente determinada postura ou, como explicitado mais adiante, determinado sujeito. Em outras palavras, como vetor ideológico, esvazia-se de sua significação teórica.

Para além dos cenários econômicos, relacionado com os três campos ou instâncias referidas, o significante elabora a forma como o sujeito se relaciona consigo mesmo e o grande Outro, já que cada afirmação constrói e sustenta sua condição de ser falante. Assim como o/a economista estabelece insígnias específicas de autoridade e intersubjetividade, de acordo com determinados códigos de autorreconhecimento e identificação, no interior da própria ordem simbólica, em cada ato ou dito, o sujeito afirma essa mesma ordem e se reafirma no interior dela. A troca simbólica, nesse caso, ratifica a variedade de regras explícitas ou implícitas, conscientes ou inconscientes, que constroem o sujeito e sua interação social. 
De que, então, se compõe a ordem simbólica? Quando falamos (ou quando ouvimos), nunca interagimos simplesmente com outros; nossa atividade de fala é fundada em nossa aceitação e dependência de uma complexa rede de regras e outros tipos de pressupostos. Primeiro há as regras da gramática, que tenho de dominar de maneira cega e espontânea: se eu tivesse de ter essas regras em mente o tempo todo, minha fala se desarticularia. Depois há o pano de fundo de participar do mesmo mundo/vida que permite que eu e meu parceiro na conversação compreendamos um ao outro. As regras que eu sigo estão marcadas por uma profunda divisão: há regras (e significados) que sigo cegamente, por hábito, mas das quais, se reflito, posso me tornar ao menos parcialmente consciente (como as regras gramaticais comuns); e há regras que ignoro que sigo, significados que ignoro que me perseguem (como proibições inconscientes). E há regras e significados cujo conhecimento não devo revelar que tenho - insinuações sujas ou obscenas que silenciamos para manter o decoro. (ZIZEK, 2006 [2010], p. 17)

Nesse sentido, considerando o significante e a tríade lacaniana, a ideologia apresenta-se como uma rede de significantes, elaborando o que se poderia chamar de o "vazio" para além da estrutura, ou, em síntese, com o elemento que falha (ou falta) na estrutura do verbo, que escapa a determinada lógica, ou que a esvazia, como o faz a temática inflacionária. É ao se tornar supérflua como instrumento analítico que a inflação apresenta sua eficácia como ferramenta ideológica e, por isso, significante. $\mathrm{O}$ significante da falta, ou a falha na rede de significantes aparece, na teoria psicanalítica, como o Um, aquele que, ao exteriorizar-se (no caso da inflação, perder força teórica), constrói o suporte e consistência de determinada ideologia (transforma-se em elemento central da narrativa neoclássica). O discurso ideológico, dessa forma, se constrói através da falta na rede de significantes que se torna em seu elemento externo, mas próximo. É a função do Um, significante da falta, único, externo e, mesmo assim, próximo. Lacan elabora essa problematização através do conceito de "ex-sistência":

[...] o conceito de existência traduz, antes de mais nada, o fato de que o elemento $S^{1}$ [significante 1] está no limite externo da estrutura. A ex-sistência provém sempre da ordem do $U m$ e da ordem da exterioridade. O Um 'ex-siste' e, assim, faz existir o conjunto ou seja, confere ao conjunto a continência necessária para que ele permaneça como uma cadeia coerente e estruturada. O Um ex-siste para que o conjunto consista. [...] A palavra 'ex-sistência' significa, pois, em primeiro lugar que se trata de um elemento único e exterior, em segundo, que esse elemento é o que faz as vezes de conjunto, e, em terceiro, que o conjunto se organiza como uma trama ligada, na qual falta um fio (furo), aquele que agora se converteu em borda. (NASIO, 1992 [1993], p. 62) 
Desse modo, considerando-se a exposição até o momento, não existe um significante isolado, perdido em si próprio, cuja existência se constrói a priori de qualquer aspecto relacional. Pelo contrário, um significante se elabora através de uma cadeia, de uma série, condicionando sua própria consistência a outros significantes. Assim, só pode ser reconhecido como significante por outro, correlacionados na mesma cadeia. É através dessa rede que a função de significante ganha relevo e é na falta de um elemento, a "falta" nessa série, que a ideologia demonstra seus contornos. O trecho acima descreve essa referência: é um elemento exterior, um significante na posição do Um, do "vazio" na própria cadeia de significantes, que elabora a consistência do conjunto como totalidade. O todo, no caso, se compõe a partir de sua própria falta: a falta constitutiva, que permite que o conjunto se estruture e possua determinada dinâmica, ou seja, gera sua consistência interna através de um objeto ou elemento externo ao movimento que a supõe. É justamente a "falta", o Um, que, na medida em que mediado como exterioridade, constrói o que se conhece como ideologia. Nesse momento, compreende-se o motivo pelo qual, para funcionar como elemento ideológico, determinado conceito precisa livrar-se de seus contornos originais de sentido. Como referido em trechos anteriores, a temática inflacionária permite visualizar esse fenômeno de maneira explícita: sua face teórica nos indaga sobre um objeto específico de análise econômica; seu vetor ideológico faz esse aspecto perder força. Surge em seu lugar a mobilização da angústia. No segundo campo, já não se trata de qualquer estudo econômico. Não há algo a explicar. Pelo contrário, a pretensão agora é elaborar e justificar determinada postura perante a realidade apresentada ${ }^{5}$. Desse modo, cumprindo a segunda função, de vetor discursivo, a inflação exterioriza-se do próprio arcabouço (teoria econômica) que elaborava seu sentido original. No entanto, é propriamente esse "exteriorizar-se" que compõe a consistência ideológica do neoclassicismo, elaborando um aparente paradoxo: justamente o momento de sua afirmação ideológica, em cujo cerne aparece a temática inflacionária, apresenta-se como sua negação teórica, já que sua efetividade como discurso ocorre através de um tema cujo significado se desloca. Compreende-se, então, o sentido da afirmação de que a totalidade, como conjunto, se constrói através de sua própria negação. E é justamente como algo externo, próximo ao sujeito, constituído por ele mesmo, mas que elabora seu discurso, que a ideologia nos fornece um tipo de proteção contra o "real cru" (ZIZEK, 2006 [2010], p. 73), que nos assola, nos protege daquilo que não podemos simbolizar e que, por isso, é compreendido como inapreensível. Nas palavras de Zizek:

[...] se o que experimentamos como "realidade" é estruturado pela fantasia, e se a fantasia serve como o crivo que nos protege, impedindo

\footnotetext{
${ }^{5}$ Diferentemente do que a ortodoxia profere, seu próprio enunciado, apresentando-se como "responsável" ante os "lenientes com a inflação", não se constrói a partir de determinada realidade, ou seja, essa postura não se manifesta como uma resposta a uma problemática econômica independente e autônoma aos olhos do/a economista. Pelo contrário: é justamente essa problemática que, através do discurso neoclássico, é criada para justificar e legitimar o embargo ao contraditório anteriormente citado.
} 
que sejamos diretamente esmagados pelo real cru, então a própria realidade pode funcionar como uma fuga de um encontro com o real. $\mathrm{Na}$ oposição entre sonho e realidade, a fantasia está do lado da realidade, e é em sonhos que nos defrontamos com o real traumático - não é que os sonhos sejam para aqueles que não conseguem suportar a realidade, a própria realidade é para aqueles que não conseguem suportar (o real que se anuncia em) seus sonhos. (ZIZEK, 2006 [2010], p. 73)

Portanto, a ideologia não apenas estrutura a "falta" na cadeia de significantes, mas também media nossa relação com o Simbólico, tornando-nos capazes de apresentar-nos como sujeitos e nos reconhecermos como tal. Desse modo, a ideologia constitui o espaço par excellence de formação de nossas próprias identificações. Nesse contexto, elucida-se a afirmação de que a crença não ideológica ortodoxa faz com que encontremos a ideologia em estado puro: a ideologia, quando abertamente negada em determinado discurso, tem sua falta reconhecida, não deslocada, sua função identificatória abertamente constituída, e é por isso que aparece como um semblante de autoridade ou uma palavra mestra ("Que voltemos aos tempos da inflação anterior ao Real?”, ou seja, "Não fale!”, “Não contraponha!”, “Não duvide!"). Assim, não é paradoxal que quando a ideologia é refutada no discurso econômico é o momento em que ela atua de maneira cristalina; mas é justamente por isso, por ser abertamente negada, que ela aparece em estado puro.

\section{LACAN, MARX E ALTHUSSER: IDENTIFICAÇÃO, ALIENAÇÃO E IDEOLOGIA}

Conforme o exposto, o artigo propõe um redimensionamento do conceito de ideologia: não mais como um "ocultamento" ou "distorção" da realidade, como apresentado pela abordagem marxiana, mas, através da constituição do próprio sujeito, a ideologia revela os elementos de formação dessa mesma realidade, trazendo consigo o que se poderia chamar de uma "falta" positiva, isto é, uma "falta" que, antes de nos esconder certo aspecto do real, nos indaga sobre ele. Nesse contexto, se a ideologia aparece como o "vazio" constitutivo de determinada rede de significantes, um "vazio" que, justamente por sua falta, estabelece os contornos do sujeito, vislumbra-se, portanto, a possibilidade de uma nova positividade, constituída a partir das identificações desse mesmo sujeito. Dessa forma, esta seção estabelece algumas relações entre identificação, sujeito e ideologia através desse novo prisma, dessa nova problematização.

A psicanálise, em geral, e Lacan, em particular, não apresentam a ideologia como um objeto de análise, ou seja, a formação e dinâmica dos discursos ideológicos não aparecem na problemática psicanalítica. No entanto, principalmente a partir da segunda metade do século XX, alguns autores utilizam este arcabouço para investigações em cujos cernes encontra-se a questão ideológica, trazendo, principalmente, o prisma identificatório lacaniano, como apresentado na seção anterior. 
Um deles é Louis Althusser. Partindo da estrutura conceitual lacaniana, ao analisar o que chamou de "aparelhos ideológicos de Estado", Althusser vincula o processo de formação ideológica à constituição do sujeito, ampliando, com isso, o sentido da ação ideológica. Na perspectiva do autor, a ideologia não apenas "funda" determinada realidade, mas o próprio sujeito para o qual esta possui sentido específico. Em outras palavras, sujeito e realidade não são entes separados. Pelo contrário, a existência de um condiciona e determina a ocorrência do outro, o que expande a compreensão da conhecida afirmação de Althusser (1970 [1996], p. 131) de que "A ideologia interpela os indivíduos como sujeitos".

Dizemos que a categoria do sujeito é constitutiva de qualquer ideologia, mas, ao mesmo tempo e imediatamente, acrescentamos que a categoria do sujeito só é constitutiva de qualquer ideologia na medida em que toda a ideologia tem a função (que a define) de "constituir" indivíduos concretos como sujeitos. É nesse jogo de dupla constituição que toda ideologia funciona, não sendo a ideologia mais que seu funcionamento nas formas matérias de existência desse funcionamento. (ALTHUSSER, 1970 [1996], p. 132)

Em síntese, o autor afirma a relação entre ideologia, identificação e sujeito, levando o espaço ideológico para além de um "ocultamento" da realidade, como exposto pela análise marxiana ${ }^{6}$. Dessa forma, afirma justamente que a formação de determinada "visão de mundo" se dá com base no relato (ou relatos) com os quais o indivíduo se identifica, elaborando os contornos do que poderia se chamar de "sujeito da ideologia". Nesse sentido, a perspectiva althusseriana traz consigo elementos importantes e que, em certa medida, demonstram um elemento de descontinuidade da teoria marxiana.

Para Marx, esse "ocultamento" está intimamente relacionado ao conceito de alienação, trabalhado a partir de Feuerbach e que desponta como o que se poderia chamar de inversão da realidade: se são as relações de propriedade efetivadas por determinado modo de produção que nos conduzem aos aspectos reais da existência, a ideologia, especificamente como fruto do trabalho alienado, ou seja, de um "produzir" dessubjetivado, cujo reconhecimento do trabalhador naquilo que cria praticamente não ocorre, dissimula tais posições. Com isso, amplia o espaço identificatório, indo além das relações de produção, porém, na medida em que o faz, obscurece-as como campo efetivo da existência. Ao longo desse debate, depreende-se um viés negativo da função ideológica, já que impossibilita que o indivíduo tome conhecimento das suas condições reais de vida e a maneira como influenciam, ou mesmo determinam, sua própria consciência. Essa separação do trabalhador com o fruto de seu trabalho, resultado de determinadas relações de propriedade, elabora justamente o "não elaborável": é nesse suposto vazio que a ideologia aparece,

${ }^{6}$ Ver, por exemplo, MARX (1932 [2007]). 
surgindo como resposta a referida "perda" identificatória. Portanto, na análise marxiana a noção de ideologia traz em si a ideia de que algo se perde, de que há um aspecto não visualizado, um momento que escapa do todo. Resumindo: para Marx, a alienação faz com que algo não se apreenda no processo de subjetivação.

Nesse cenário, Althusser traz, para além das "condições efetivas de existência", que considera válidas, já que parte também do arcabouço marxiano, uma alteração no viés do discurso ideológico no interior da teoria social: como já referido, se a abordagem marxiana enfatiza o viés negativo da ideologia, como "ocultamento" e/ ou "encobertamento" da realidade, a construção de Althusser, partindo de Lacan, torna possível uma aproximação positiva do conceito, tendo em vista o fato de que é justamente através de determinada visão ideológica que o indivíduo constrói sua consciência. Em síntese, se na primeira abordagem, a ideologia "mascara", na segunda, ela constitui o sujeito, na medida em que estão aí as bases de suas identificações. Assim, o vazio, o silêncio ideológico surge como condição de possibilidade para o surgimento de uma nova positividade: a constituição do próprio sujeito. É nesse contexto que se apresenta a principal função da temática inflacionária no cerne do discurso neoclássico: estabelece a unidade discursiva da ortodoxia econômica, elaborando, para tanto, a identificação central do/a economista ortodoxo/a.

\section{A FICÇÃO DE KARL POPPER E A FANTASIA NEOPOSITIVISTA}

Desse modo, considerando o até aqui exposto, Karl Popper se transforma no verdadeiro utopista ${ }^{7}$, assim como os liberais e seu sonho tecnicista: a ontologia econométrica da história, fruto de uma análise e de um arcabouço teórico construídos sem intervenções ideológicas, não é nada mais que uma ficção, que a ideologia aparecendo de maneira cristalina. Também o sonho neopositivista de exclusividade científica de relações matematizáveis só demonstra o quão a ideologia está intrinsecamente ligada à economia política: o discurso ideológico constrói o sentido das respectivas teorias econômicas, fundamenta suas articulações e elabora suas interlocuções. Assim como a fantasia neoclássica de uma economia sem regulações surge como uma inversão ideológica (a própria manutenção do discurso de livre mercado como ideologia hegemônica pressupõe a existência de intervenções que impossibilitem esse mesmo mercado, sob pena de destruição da totalidade do sistema econômico, como expõe, por exemplo, POLANYI, 2012 [1944]), a condição de existência da verdade de Popper é sua própria inviabilidade. Da mesma forma como a realização de uma utopia ocorre através de seu próprio fechamento, ou seja, com sua dissolução como projeção narcísica, o sonho popperiano e neopositivista corrobora a si mesmo afirmando o que supostamente combate: a ideologia. É por isso que, quando afirma sua exclusividade científica nada mais faz do que

\footnotetext{
${ }^{7}$ Ver, por exemplo, POPPER (1957 [1980]).
} 
reestabelecer a crença que havia negado: a possibilidade de uma análise capaz de se construir para além do discurso idológico.

Essa afirmação "não ideológica" popperiana e neopositivista demonstra os limites e interdições na base da teoria econômica ortodoxa. Com base na seção anterior, o próprio esvaziamento da função ideológica impede uma superação positiva da economia mainstream, cujo resultado é seu esgotamento em si mesma, o que, de fato, manifesta-se através de sua negação do "outro" como condição própria de existência. Em outras palavras, a rejeição da ideologia aparece como o próprio cerne do discurso ortodoxo, constituindo, a partir dessa premissa, sua consistência e injunções básicas. Por outro lado, a contrapartida de tal postura é o bloqueio, não apenas do outro, o que diverge, mas também a qualquer tipo de devir positivo de seus aspectos centrais. Assim, o "custo" da hegemonia ortodoxa é seu eterno debate consigo mesma, elaborando em bases muito estreitas suas possibilidades de renovação teórica. Em síntese, ao refutar o outro, a ortodoxia refuta parte de si mesma, já que a própria interdição, para ocorrer, necessita afirmar uma identificação básica: tanto ortodoxos/as quanto heterodoxos/as debruçam-se sob o mesmo objeto, qual seja, a economia brasileira. Negar a legitimidade de determinada interpretação de um objeto específico, é negar parte desse mesmo objeto, o que, de certa forma, afeta seu desenvolvimento teórico. Não nos esqueçamos o referido na introdução desse artigo: o imaginário sobre os atuais problemas econômicos são os atuais problemas econômicos, ou seja, a crítica a determinada análise econômica se constrói como crítica ao próprio objeto em estudo. Não existe inflação sem o olhar do outro e a ortodoxia, ao não reconhecer esse olhar, não reconhece o próprio fenômeno. O resultado é a apresentação de um debate deformado entre os supostos "ideológicos" e os "não ideológicos". Entre os que propõem saídas políticas e outros, alternativas puramente técnicas. No entanto, ironicamente (ou não), é nessa afirmação da ideologia como algo externo ao discurso que esta aparece de maneira cristalina, em estado puro. Ao fazer essa afirmação, o neoclassicismo não faz nada mais do que apresentar de modo explícito sua face ideológica. Nesse mesmo contexto, pode-se afirmar que, contrariando o que correntemente se afirma na literatura econômica, são Popper e os neopositivistas que se inundam de afirmações ideológicas e as escancaram na medida em que as negam. Assim, ao negar a ideologia que os supõem, trazem em si um discurso inócuo, esvaziado, desengajado em seu próprio espaço. Essa percepção de um vazio constituinte, de uma falta não falada (ou seja, da ideologia não reconhecida), mas sentida, inunda o debate econômico brasileiro.

\section{A ORTODOXIA E O DEBATE INTERDITADO: A INFLAÇÃO COMO UNIDADE DISCURSIVA DO NEOCLASSICISMO}

A argumentação até aqui elaborada trouxe à tona algumas questões importantes: a ideologia se constrói como uma "falta" positiva, como uma "perda", um "silêncio" capaz de afirmar algo, no caso, o próprio sujeito; a negação da ideologia 
apenas a revela em seu estado puro, de maneira cristalina, na medida em que afirma a própria falta que a constitui. Surge, assim, o esvaziamento do conceito (de determinado conceito, no caso), que se opera através de um significante e seu semblante de autoridade; teorias que operam através dessa dinâmica nada mais fazem que revelar todo o seu caráter ideológico e a inversão que elaboram. Como afirmado anteriormente, a condição de existência tanto do neopositivismo como da utopia liberal, se baseiam na sua impossibilidade de concretização. Tendo em vista esse arcabouço, passa-se a analisar o debate econômico nacional de maneira mais detalhada. Considerando que, ao contrário do que se possa imaginar, nossa discussão hoje se encontra ideologicamente interditada, bloqueada por um tema em especial: a questão inflacionária. De maneira mais específica, o eterno diagnóstico de inflação de demanda que perpassa implicitamente a maioria das análises ortodoxas e que sustenta o chamado tripé macroeconômico: superávit primário, metas de inflação e câmbio flexível.

Atualmente essa mesma discussão tem adotado tom monocórdio, principalmente quando se refere a diagnósticos que baseiam a elaboração de política econômica. A tese central formulada no final dos anos 1990 defende a existência de uma inflação de demanda, ou seja, uma elevação da procura de bens e serviços que excede a oferta em dado momento. O cerne do combate à aceleração inflacionária parte desse ponto, objetivando um desaquecimento da atividade econômica, tendo em vista uma baixa no nível geral de preços. Em outras palavras, o modelo de política econômica empregado supõe, implicitamente, o aquecimento da demanda agregada, mesmo em quadros abertamente recessivos, como vistos em 2015 e 2016. O remédio, nesses casos, é em muito pior que a própria doença: uma política de austeridade, de ajuste fiscal, com efeitos recessivos no crescimento do produto, elevação do desemprego e queda acentuada da renda. Tem-se, então, que para o combate à inflação implementam-se políticas ainda mais deletérias que a própria causa. Essa ideia subjacente ao modelo não é fruto de uma discussão pública, aberta, mas resultado da visão linearmente construída do neoclassicismo, da ideologia que guia as formulações de cunho ortodoxo. Nesse cenário, indaga-se: de que forma a conjuntura acima descrita corrobora a argumentação construída nas seções anteriores? Reafirmando a hipótese principal desse trabalho, isso ocorre a partir da negação ideológica da ortodoxia, que esvazia o próprio conceito de que trata, no caso, a inflação (apresentada através da tese de inflação de demanda), transformando-o no que Lacan chamava, e já apresentado, de significante, trazendo em si a palavra mestra, a inflação que é, que não aceita dúvidas e que baseia sua argumentação não numa suposta racionalidade ou superioridade lógica, mas antes num aparente acesso a um código ético e moral. No caso brasileiro, a existência de uma memória inflacionária (na maioria das vezes utilizada como um "pavor inflacionário", tal é a angústia criada em torno do tema), resquício do final da década de 1980 e início dos anos 1990, cria um cenário propício para a interdição de qualquer debate mais complexo sobre desenvolvimento econômico ou que proponha outras metas importantes de política econômica. A questão central na análise se apresenta na medida em que a temática inflacionária aparece como a principal "ponta de 
lança" da ortodoxia brasileira, utilizada para interditar possíveis contrapontos ou discursos divergentes. Com isso, mostra-se um debate deformado, surgindo como uma disputa entre aqueles preocupados com a "saúde monetária" do país (ortodoxos/as) e os lenientes com a aceleração inflacionária (heterodoxo/ass). Entre os "sensatos" e os "irresponsáveis". Um conflito entre a "seriedade" e o "populismo". Afinal, quem poderá ser contra o combate à inflação?

O cenário apresentado acima descreve a inserção do significante no interior do debate econômico brasileiro. Como em qualquer discussão ideológica, os discursos apresentam sentidos que vão além da palavra. Ao aparecer como significante, como a inflação que é e só por ser deve ser combatida, assim como seus supostos defensores, a temática inflacionária serve como referencial que separa o "nós" e os "outros". Mais que isso: ao esvaziar sua eficácia teórica e aparecer como significante, a inflação constrói a consistência ideológica da ortodoxia brasileira, derivando desse elemento seus demais pressupostos, como, por exemplo, injunções sobre política fiscal e perfil de Estado. Constitui, a partir desse ponto, uma das identificações centrais do discurso ortodoxo e elemento basilar no autorreconhecimento entre os/as próprios/as economistas ligados/as às correntes neoclássicas, já que compõem as insígnias específicas da ortodoxia. Nesse contexto, a inflação torna-se exterior ao discurso, perdendo força como instrumento analítico, mas, justamente por isso, elabora a síntese referencial da ortodoxia. Apresenta-se, assim, o elemento externo, mas íntimo da ideologia que permeia o neoclassicismo.

Portanto, a função primordial da temática inflacionária é construir a unidade discursiva da ortodoxia brasileira, constituindo, com isso, o aspecto essencial na identificação do/a economista ortodoxo/a. Desse modo, pode-se afirmar que, em suas bocas, esvai-se o fenômeno e encontra-se o significante.

\section{A ORTODOXIA PARA ALÉM DA PALAVRA: O SEMBLANTE DOS JUROS}

Considerando o exposto até o momento e levando-se em conta o papel específico da inflação no discurso ortodoxo, pergunta-se: para além do fenômeno, o que efetivamente se discute quando o "significante inflacionário" aparece? Mais precisamente: a interdição da discussão ocorre em defesa do quê? É evidente que o surgimento da temática inflacionária estabelece o não aparecimento do debate efetivo. Como já afirmado, essa é sua função. No entanto, deve-se buscar o que se esconde por trás da forma de diálogo. Nesse contexto, investigando o modelo de política econômica dos "reais" e "verdadeiros" combatentes da inflação, ou seja, os principais instrumentos de política que defendem para uma suposta preservação da estabilidade monetária, a análise nos mostra que, sob o véu da contenda contra a elevação do nível geral de preços, surge a guarda tácita da atual prevalência dos juros na dinâmica da economia brasileira. Em outras palavras: a "memória inflacionária” é mobilizada não para a diminuição, de fato, de uma possível aceleração inflacionária (o que essencialmente exigiria mudanças estruturais na economia), mas antes para a defesa e manutenção de uma forma de política econômica que, ao 
ter em sua face a luta contra elevações nos índices gerais de preços, busca legitimidade para a dominância de um grupo específico do capitalismo nacional: o rentismo. Em resumo: os contornos do discurso ortodoxo baseiam-se na prevalência do setor financeiro no financiamento da economia brasileira e seu peso determinante da acumulação nacional.

Historicamente, a atual função discursiva da inflação no debate brasileiro forma-se paulatinamente durante a década de 1990, intimamente ligada ao processo de financeirização econômica. A implementação do Plano Real e a abertura da economia, base da âncora cambial com o dólar norte-americano ${ }^{8}$, mais do que conseguir a queda do nível geral de preços, estruturou o modelo de política que aumentou a dependência do país aos movimentos da conta capital para a obtenção de equilíbrio do balanço de pagamentos ${ }^{9}$. É nesse momento, com juros subindo vertiginosamente, levando consigo a dívida pública ${ }^{10}$, que se sedimentam as bases para a dominância financeira. A forma do modelo de política econômica que expressa esse fenômeno é o anteriormente citado tripé macroeconômico: superávit primário, metas de inflação e câmbio flexível. Nesse cenário, a preocupação na manutenção de baixo nível geral de preços é congruente com a estabilidade no valor dos ativos (financeiros e reais), bem como a diminuição de perdas cambiais, fruto de uma possível deterioração do poder de compra da moeda brasileira.

Nesse contexto, um dos primeiros trabalhos a criticar essa problemática e a sistematizar possíveis alterações na política monetária, com base no impacto dos juros na dinâmica econômica nacional, foi o de BRESSER e NAKANO (2002), onde defendem a necessidade de controle da taxa básica para dirimir déficits externos, tendo em vista sua influência nos movimentos da taxa de câmbio. Os autores ainda propõem, conjuntamente com a redução dos juros, a adoção de uma política comercial ativa e uma reestruturação do setor industrial, capaz de, junto com a desvalorização cambial oriunda da diminuição da taxa básica, obter o equilíbrio externo através do aumento das exportações. O artigo gerou certa polêmica, com alguns economistas ortodoxos respondendo aos autores citados. BACHA (2002) criticando o "eterno dilema da taxa de câmbio" (BACHA, 2002, p. 2), problematizou sua relação com uma eventual queda dos juros e o nível geral de preços, argumentando sobre as supostas consequências de sua desvalorização e minimizando a influência do Banco Central na determinação dos juros, agregando a esse cenário a percepção de risco dos investidores. Segundo o autor, é um círculo vicioso que em muito dificulta o financiamento de longo prazo. Já LOPES (2002) adota um tom mais ameno, mas, como já exposto em BACHA (2002), também problematiza a ligação entre redução de juros, desvalorização cambial e aumento dos índices de inflação, bem como de mecanismos de indexação. No entanto, o autor considera que "[...] BN tem uma proposta equivocada no que diz respeito à políti-

\footnotetext{
${ }^{8}$ Ver, por exemplo, FLIGENSPAN (1998).

${ }^{9}$ Ver, por exemplo, CARNEIRO (2007a, 2007b).

${ }^{10}$ Ver, por exemplo, FERRARI (2001).
} 
ca de juros, mas estão corretos na proposta de uma política comercial ativa" (LOPES, 2002, p. 11). Em outras palavras, os dois autores centram suas críticas em uma possível redução dos juros e o impacto dessa medida no nível geral de preços, estabelecendo reduzidas margens para a política monetária. Nos dois casos, é uma suposta elevação dos preços que inviabilizaria uma redução acentuada dos juros. Não é a toa, no caso, que BACHA (2002) defende o desenvolvimento de um mercado de capitais de longo prazo e LOPES (2002) critica a proposição de BRESSER e NAKANO (2002) de uma "coordenação central” (BRESSER e NAKANO, 2002, p. 165) do Banco Central com outros órgãos, vendo no que chamaram de perda de independência "de fato", um retrocesso institucional. É a inflação, no caso, que opera como argumento central contra a redução dos juros. $\mathrm{O}$ fato, em si, não surpreende, tendo-se a argumentação até aqui já exposta. Nesse caso, surge a inflação que é, operando como significante, de maneira idealizada, projetada. A inflação que virá é sempre pior do que aquela realmente encontrada no cotidiano. É explícito, nesse caso, que os fatores mobilizados são o medo, a angústia e a ansiedade, só possíveis pela não ocorrência do fenômeno, mas por sua projeção. Esses aspectos corroboram a afirmação realizada de que a temática inflacionária abrange um deslocamento: na ideologia não aparece o fenômeno econômico, sua aparência, mas seus vetores esvaziados e é em meio a esse cenário que a análise nos leva a crer que a "memória inflacionária" opera, no nível ideológico, na defesa de interesses que vão além de seu uso na teoria econômica. O neoclassicismo brasileiro carrega consigo o semblante dos juros ${ }^{11} \mathrm{e}$ de sua atual prevalência na dinâmica econômica nacional, fazendo com que a defesa enfática do combate à inflação torne-se, no discurso ortodoxo, a afirmação de um certo tipo de gestão da política econômica (como demonstrado no exemplo acima). Nesse sentido, como resposta à pergunta feita no início dessa seção apresenta, a argumentação de que, de fato, quando se defende a prioridade ao combate à aceleração inflacionária, fala-se efetivamente sobre a primazia do capital financeiro e seus interesses ligados à determinado formato de política econômica, mais especificamente, uma política monetária restritiva, baseada em uma taxa SELIC elevada, capaz de lastrear a rentabilidade dos ativos financeiros. No debate econômico brasileiro, combate à inflação, sob a ótica da ortodoxia, significa maiores ganhos no mercado de títulos.

Portanto, como exposto até o momento, considera-se que a forma do debate esconde justamente sua não ocorrência. Em outras palavras, apesar da existência dos contornos da discussão, a impossibilidade de expor questões centrais que servem como base de um contraponto consistente, faz com que, na essência, projete-se um mecanismo de aparências. Nesse cenário, perguntas relevantes não são feitas: A sociedade brasileira não suportaria um maior nível geral de preços objetivando

\footnotetext{
${ }^{11}$ Ao ler LISBOA (1997, p. 6) quanto aos "fios de marionete que controlam as minhas escolhas", é importante lembrar que, ao se apresentar determinado discurso ideológico, assume-se, em certa medida, um pouco de sua própria história. As atualizações conceituais (parte de seu processo de reflexão) superam as contradições anteriores, mas não as apagam.
} 
um crescimento econômico mais elevado? O central da política monetária deve ser efetivamente o controle inflacionário? O regime de metas de inflação é o mais adequado para a realidade do país? Questões centrais, mas que ameaçam aspectos importantes do imaginário elaborado durante a década de 1990 e que, por isso, não devem (segundo alguns segmentos da economia nacional) ter eco no debate econômico nacional. Nesse ponto demonstram-se, de fato, as reais consequências da interdição exposta. Nota-se que a inflação, elemento externo ao sujeito, é justamente o que o reafirma e sedimenta o discurso ortodoxo. Ocupa, nesse sentido, a "falta" apresentado anteriormente e que define a ideologia como o "vazio" para além da palavra. No entanto, o elemento que expõe esse mecanismo não é a função específica da temática inflacionária, nem mesmo o fato de se apresentar como veículo ideológico, mas a própria negação do referido mecanismo. A ortodoxia, no momento em que nega seu elemento ideológico, expõe as interdições que gera. É nesse momento que o discurso ortodoxo manifesta seu caráter ideológico, justamente quando o recusa, evidenciando a própria falta da qual ele se constitui. Dessa forma e justamente nesse instante, a ideologia revela-se em estado puro.

\section{CONCLUSÃO}

O artigo discorre sobre o atual momento do debate econômico brasileiro, apresentando sua interdição basilar: a inflação como significante e, portanto, vetor ideológico. Nesse ponto, a discussão continua na forma, em seus contornos, porém se esvai no conteúdo, impossibilitando a construção de um diálogo genuíno. A inflação como significante manifesta, para além da palavra e variáveis, um aspecto primordial da dinâmica da economia brasileira: a prevalência dos juros, entre os ganhos de renda. A mobilização da angústia, a partir da "memória inflacionária" dos brasileiros/ as, elabora, justifica e legitima o modelo de política econômica adotado no final da década de 1990: metas de inflação, superávit primário e câmbio flexível. Nesse contexto, além de servir como identificação básica, como momento de unidade que elabora a síntese do/a economista ortodoxo/a, corrobora uma forma de gestão econômica capaz de apoiar um grupo bastante restrito da economia nacional, qual seja, o rentismo. Apresenta-se, assim, como uma narrativa ideológica. Contudo, é a negação desse aspecto, conforme demonstrado pela análise, que revela sua ideologia intrínseca em estado puro: à "ex-sistência" lacaniana subsiste o "vazio" constitutivo do discurso ideológico. A inflação cumpre esse papel: como veículo ideológico perde relevância analítica, mas, justamente por isso, constitui a base da narrativa ortodoxa. Esse é o cerne da formação das ideologias. A própria crença na neutralidade científica é, em si, uma projeção de parcela dos/as economistas, isto é, sua visão de si de maneira idealizada ou, pode-se dizer, ideológica. Nesse momento, é possível perguntar: como desenvolver um debate genuíno, onde o "para além das palavras" torne-se verbo? A condição primordial de possibilidade é o "saber do que se fala". Desse modo, tem-se, como passo básico, o reconhecimento do elemento ideológico da argumentação e, a partir desse instante, a construção do reconhecimento do "outro", 
do que diverge, assumindo assim sua própria perspectiva argumentativa. Portanto, como afirmado na introdução deste artigo, o que ocorre efetivamente é a constituição de campos discursos diferentes baseados nas próprias verdades virtuais que constroem, ou seja, de suas ideologias. Assumir essa condição faz parte do debate.

\section{REFERÊNCIAS BIBLIOGRÁFICAS}

ALTHUSSER, Louis (1970 [1996]). “Ideologia e aparelhos ideológicos de estado (Notas para uma Investigação)". In: ZIZEK, Slavoj (org.) (1994 [1996]). Um Mapa da Ideologia. Rio de Janeiro: Contraponto.

BACHA, Edmar (2002). "Comentários sobre 'Uma Estratégia de Desenvolvimento com Estabilidade”". Disponível em: http://www.bresserpereira.org.br/terceiros/autores/02.2-Bacha,Edmar-ComentarioEstratCrescEstabilidade.pdf. Acesso em: 08 de fevereiro de 2017.

BRESSER-PEREIRA, Luiz C. (2010). “A descoberta da inflação inercial”. Revista de Economia Contemporânea, 14 (1): 167-192.

BRESSER-PEREIRA, Luiz C. e NAKANO, Yoshiaki (1984). "Fatores aceleradores, mantenedores e sancionadores da inflação". Revista de Economia Política, 4 (1): 5-21.

BRESSER-PEREIRA, Luiz C. e NAKANO, Yoshiaki (2002). "Uma estratégia de desenvolvimento com estabilidade". Revista de Economia Política, 4 (3): 146-180.

CARNEIRO, Ricardo (2007a). "Globalização e integração periférica”. Texto para Discussão no 126. Campinas: IE/UNICAMP.

CARNEIRO, Ricardo (2007b). "Dinâmica de crescimento da economia brasileira: Uma visão de longo prazo". Texto para Discussão no 130 . Campinas: IE/UNICAMP.

FERRARI FILHO, Fernando (2001). "O legado do Plano Real: uma estabilização sem crescimento econômico?”. Análise Econômica, 19 (35): 5-21.

FLIGENSPAN, Flavio. "Uma visão global da economia brasileira durante a vigência do Plano Real: Avanços, impasses e um cenário de crescimento com exclusão”. IndicadoresEconômicos FEE, 26 (1): $102-143$.

FREUD, Sigmund (1905 [1996]). Os Chistes e sua Relação com o Inconsciente. Rio de Janeiro: Imago Editora.

FREUD, Sigmund (1905 [1996]a). Três Ensaios sobre a Sexualidade. Rio de Janeiro: Imago Editora.

FRIEDMAN, Milton (1953 [1966]) “The methodology of positive economics". Essays In Positive Economics. Chicago: Editora da Universidade de Chicago. 3-16, 30-43.

KEYNES, John Neville (1890 [1955]). The Scope and Method of Political Economy. Nova York : Kelley \& Millman.

LACAN, Jacques. (1966 [1998]). Escritos. Rio de Janeiro: Zahar.

LARA RESENDE, André (1989). "Da inflação crônica à hiperinflação: observações sobre o quadro atual", Revista de Economia Política, 9 (1): 7-20.

LISBOA, Marcos (1997). "A miséria da crítica heterodoxa, primeira parte: sobre as críticas”. Revista de Economia Contemporânea, 1 (2): 5-66.

LOPES, Francisco (2002). “A proposta Bresser-Nakano para o futuro da política econômica”. Boletim de Conjuntura, Macrométrica.

MARX, Karl (1932 [2007]). A Ideologia Alemã. São Paulo: Martins Fontes

NASIO, Juan-Davi (1992 [1993]). Cinco Lições Sobre a Teoria de Jacques Lacan. Rio de Janeiro: Zahar.

NASSIF, Luís (2016). As Marolas Pré-Reunião do Copom. Disponível em: http://jornalggn.com.br/noticia/as-marolas-pre-reuniao-do-copom. Acesso em: 20 de Janeiro de 2016.

POLANYI, Karl. (1944 [2012]). A Grande Transformação: As Origens da Nossa Época. Rio de Janeiro: Campus.

POPPER, Karl R. (1957 [1980]). A Miséria do Historicismo. São Paulo: Editora da USP.

ZIZEK, Slavoj (1996 [2010]). Como Ler Lacan.Rio de Janeiro: Zahar. 